\title{
REVIEW
}

\section{An integrated approach in the diagnosis of smoking-related interstitial lung diseases}

\author{
Antonella Caminati*, Alberto Cavazza ${ }^{\#}$, Nicola Sverzellati ${ }^{\star}$ and Sergio Harari*
}

ABSTRACT: Cigarette smoke consists of several chemical compounds with a variety of effects in many organs. In the lung, apart being the main cause of chronic obstructive pulmonary disease, carcinoma and idiopathic spontaneous pneumothorax, tobacco smoke is associated with interstitial lung diseases (ILDs), including respiratory bronchiolitis-associated ILD (RB-ILD), desquamative interstitial pneumonia (DIP), pulmonary Langerhans' cell histiocytosis (PLCH), idiopathic pulmonary fibrosis, acute eosinophilic pneumonia, ILD in rheumatoid arthritis and pulmonary haemorrhage in Goodpasture syndrome.

This review will focus on the diseases with a stronger epidemiological association with tobacco smoke, namely RB-ILD, DIP and PLCH. Although the exact pathogenetic evidence linking smoking with these disorders is still not completely understood, there is growing evidence that tobacco smoke targets the terminal or respiratory bronchioles in these diseases, and the differences are reflective of the degree of severity of small airway and parenchymal reaction to the smoke exposure.

Despite considerable clinical, radiological and histological overlap between RB-ILD, DIP and $\mathrm{PLCH}$, it is useful to retain the separate classifications for prognostic and therapeutic implications.

KEYWORDS: Desquamative interstitial pneumonia, interstitial lung diseases, Langerhans' cell histiocytosis, respiratory bronchiolitis, smoking
T he influence of tobacco smoke on human health is still an important problem in the developed world. Complex inflammatory processes and changes in the immune system are crucial in the pathogenesis of smoking-related disorders, such as chronic obstructive pulmonary disease (COPD), emphysema, lung cancer and atherosclerosis. The term asymptomatic smoker implies a healthy smoker, i.e. without clinical symptoms of chronic bronchitis and with normal values of pulmonary function tests, which is differentiated from a smoker with signs of COPD or interstitial diseases. However, the line of division is difficult to define because of the possibility of asymptomatic bronchiolitis [1]. The role of tobacco smoke in the pathological processes of small airways is well documented $[2,3]$. The cause-effect relationship between a history of cigarette smoking and interstitial diseases is a more recent acquisition. Respiratory bronchiolitis $(\mathrm{RB})$ is present pathologically in most smokers, but

very few of them experience symptoms. $R B$ is characterised by airway-centred accumulations of macrophages containing fine, granular yellowbrown cytoplasmic pigments ("smoker's macrophages") within distal bronchioles, alveolar ducts and adjacent alveolar spaces. Cytoplasmic pigmentation is variable and correlates with the numbers of pack years smoked [4]. RB represents a highly specific physiological response to smoking. RB-associated interstitial lung disease (ILD) is the term used to describe smokers who become symptomatic secondary to RB [5]. RB-ILD is an uncommon ILD that occurs in a small proportion of smokers [5]. Because of the significant overlap in clinical, radiological and histological features between RB-ILD and desquamative interstitial pneumonia (DIP), these entities are considered a pathomorphologic continuum, representing different degrees of severity of the same disease process [6-10]. However, there are prognostic reasons for continuing to separate RB-ILD from

For editorial comments see page 171.

Some of the results of this article have been previously presented at the 4th International meeting on Pulmonary Rare Diseases and Orphan Drugs, Milan, Italy, February 25-26, 2011.

\section{AFFILIATIONS}

*U.O. Pneumologia e Terapia SemiIntensiva Respiratoria, Servizio di Fisiopatologia Respiratoria ed Emodinamica Polmonare, Ospedale San Giuseppe - MultiMedica, Milan \#U.O. di Anatomia Patologica Arcispedale Santa Maria Nuova IRCCS, Reggio Emilia, and -Dipartimento di Scienze Radiologiche, Sezione di Diagnostica per Immagini, Università degli Studi di Parma, Parma, Italy.

\section{CORRESPONDENCE}

S. Harari

U.O. di Pneumologia

Ospedale San Giuseppe -

MultiMedica

via San Vittore 12

20123 Milan

Italy

E-mail: sharari@ilpolmone.it

Received:

April 252012

Accepted after revision:

June 072012

\section{PROVENANCE}

Submitted article, peer reviewed. 
DIP when possible. The mortality of patients with DIP is $6-30 \%$, while only rarely have patients with RB-ILD been reported to die of their disease [5, 11-15]. Additionally, patients with DIP may develop acute exacerbations [16-18]. DIP is one of the rarest idiopathic interstitial pneumonias and is characterised by the diffuse accumulation of large numbers of pigmented macrophages in alveolar spaces associated with interstitial inflammation and/or fibrosis [19]. In the majority of cases, DIP is considered to be a smoking or dust inhalation-related interstitial pneumonia. The association of organ-specific immunological diseases and elevated antinuclear antibody, observed in some cases, and bronchoalveolar lavage (BAL) eosinophilia/ neutrophilia in DIP suggest that the pathogenesis may be immunologically mediated $[13,20]$. Pulmonary Langerhans' cell histiocytosis $(\mathrm{PLCH})$ is a non-neoplastic reactive process to cigarette smoke. It is characterised by multiple stellate cellular nodules centred around, or adjacent to, small airways. Over time, these lesions show increasing amounts of stellate fibrosis with cyst formation [21, 22]. The cystic cavities represent the highly distorted bronchiolar lumen resulting from the destruction of the airway walls by Langerhans' cell (LC) granuloma [23]. The relationship of smoking with RB-ILD, DIP and PLCH has been largely established on the basis of epidemiological evidence. These diseases are correctly considered as distinct and separate conditions in the classification of ILDs, but these three entities share a number of clinical, radiological and pathological features, suggesting that they represent a spectrum of patterns of ILDs occurring in predisposed individuals who smoke. The association of pulmonary emphysema with non-specific interstitial pneumonia (NSIP) provides support for cigarette smoking as a pathogenetic factor in a subset of NSIP patients in recent studies [24-27]. Acute eosinophilic pneumonia is a dramatic response to recent onset smoking in a small number of individuals [28]. Recently, a new entity has been highlighted, combined pulmonary fibrosis and emphysema (CPFE) [29]. Not just a distinct phenotype of idiopathic pulmonary fibrosis (IPF), the syndrome of CPFE is characterised by the association of distinct features, including: tobacco smoking; severe dyspnoea; unexpected near normal lung volumes; severely impaired diffusing capacity of the lung for carbon monoxide $(D \mathrm{~L}, \mathrm{CO})$; hypoxaemia at exercise; characteristic radiological features (centrilobular and/or paraseptal emphysema, and diffuse interstitial aspects suggestive of pulmonary fibrosis at the lower lobes); frequent association with pulmonary hypertension; and poor prognosis [30-32]. This review will focus on the diseases with a stronger epidemiological association with smoke, namely RB-ILD, DIP and PLCH.

\section{HISTOLOGICAL-RADIOLOGICAL CORRELATIONS $R B$ and other abnormalities}

From the pathologist's perspective, the most characteristic effect of tobacco smoke on lung parenchyma is $\mathrm{RB}$, consisting of the presence of bronchioles and peribronchiolar alveoli of finely pigmented, iron-containing (smoker's) macrophages in the lumen (fig. 1a) $[4,33,34]$. The degree of pigmentation is related to the number of pack-years smoked [4]. In heavy smokers, particularly marijuana smokers [35], the pigment can become coarser and the distinction with haemosiderin due to chronic haemorrhage may be difficult to identify on purely histological grounds, therefore, clinical evidence is required. The changes are patchy at low magnification, generally with a striking bronchiolocentric distribution (fig. 1b); however, smoker's macrophages may variably extend to the peripheral alveoli, occasionally involving the entire lobule (fig. 1c). The amount of pigmented macrophage accumulation within respiratory bronchioles observed histologically correlates with the profusion of centrilobular nodules on high-resolution computed tomography (HRCT) [36]. Such nodules are poorly defined and separated from the pleural surfaces, fissures and interlobular septa by several millimetres (fig. 1d) [37]. The intensity of macrophage accumulation in the alveoli and alveolar ducts is linked to the extent of ground-glass attenuation on HRCT [36]. However, ground-glass opacities do not exclusively correspond to macrophage accumulation at histology as they may also be caused by mild interstitial inflammation and/or fibrosis [36].

Frequently, smoker's macrophages are associated with subtle histological features of chronic bronchiolitis, including mild lymphocytic inflammation and mild fibrosis of the bronchiolar wall and surrounding alveolar septa; sometimes with rigidity and distortion of the bronchiolar lumen, bronchioloectasia and mucostasis. Although these changes can be prominent enough to be histologically indistinguishable from constrictive bronchiolitis, they generally only have minor clinical consequences in the form of mild airflow obstruction. It is conceivable assuming that scattered lobules of reduced attenuation on HRCT, confirmed as lobular air trapping on expiratory computed tomography scanning, may be correlated with the remodelling of both membranous and respiratory bronchioli. However, air trapping is not as extensive on HRCT as is observed in other mixed interstitial and small airways diseases [38]. Air trapping may be accompanied by a slight thickening of the larger (e.g. subsegmental) intralobar airways, possibly reflecting changes of chronic bronchitis [39].

$\mathrm{RB}$ is very frequent in smokers, and probably is the most sensitive and specific histological marker of tobacco smoke. In a study on 156 surgical specimens [4], RB was found in all 83 current smokers and in only two out of 24 never-smokers; however, the smoking history was controversial in both groups. Interestingly, RB was also present in $\sim 50 \%$ of ex-smokers, sometimes persisting many years after smoking cessation. Of the 109 patients who had RB, RB was the cause of an ILD in only two (RB-ILD and DIP in one patient each). In other words, RB is generally a histologically incidental finding in smokers (as the biopsy is obtained for another reason, for example, a carcinoma), and only rarely does RB cause an ILD. Although patients with ILDs have, in general, more severe histological alterations, histology alone is unable to predict the presence of ILD in a single case. Similarly, RB and RB-ILD cannot be distinguished solely from the nature of HRCT abnormalities, as there is no arbitrary cut-off in HRCT disease extent at which RB becomes RB-ILD. However, the extent of disease on HRCT images should be taken into account when reaching the decision that clinically significant ILD (i.e. RB-ILD) is present [40]. The distinction between $\mathrm{RB}$ and RB-ILD varies greatly in the literature. Recently, CHURG et al. [41] proposed a strict definition of RBILD, which we concur with; therefore, following this definition, RB-ILD should be restricted to smokers with restrictive or mixed obstructive and restrictive functional abnormalities, with a marked decrease in diffusing capacity with minimal airflow obstruction, or with ground-glass opacities/centrilobular nodules plus reticulation at HRCT, and no other lesions besides RB on biopsy. 

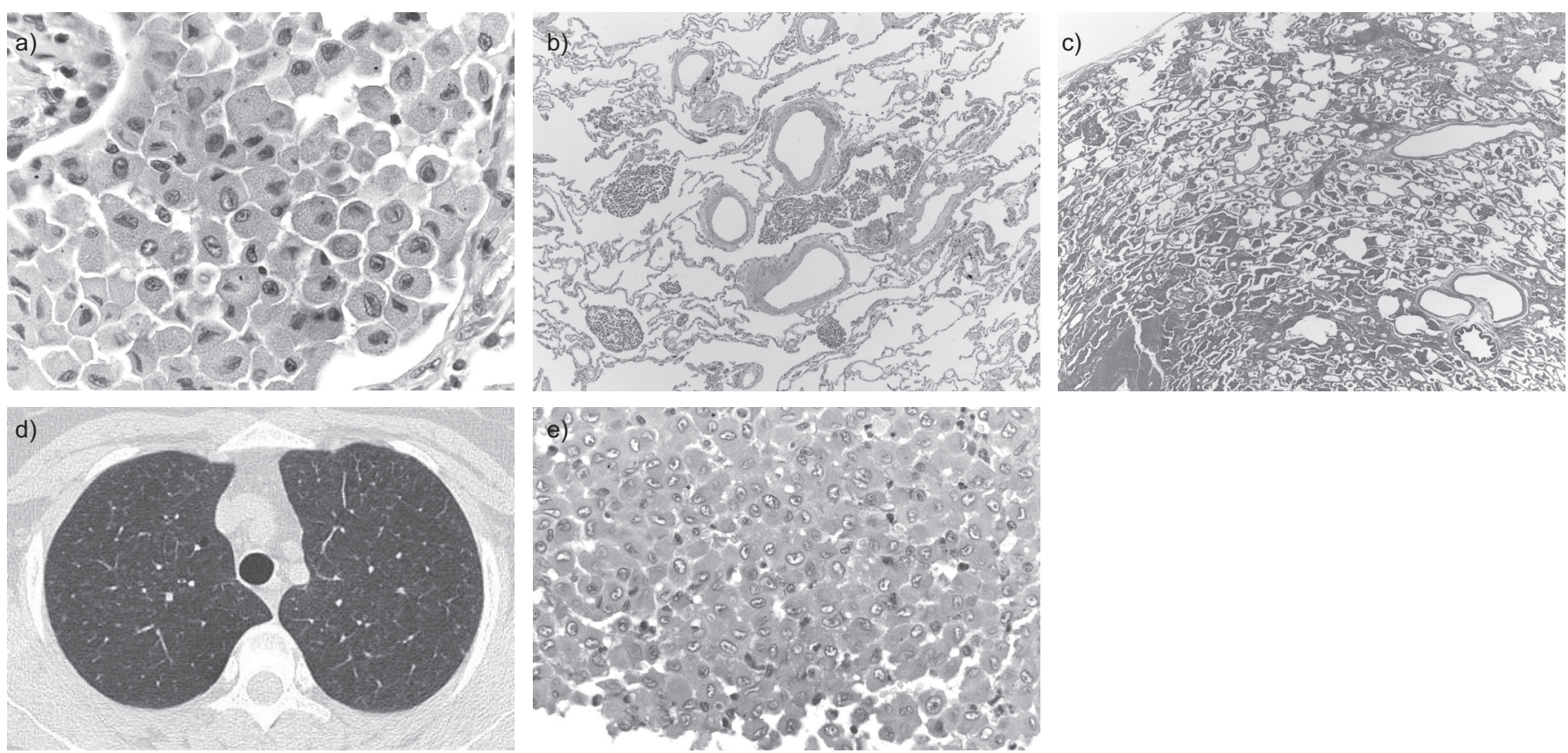

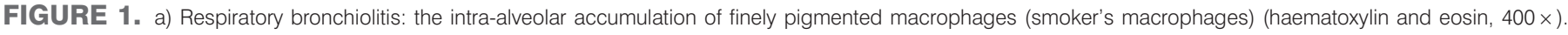

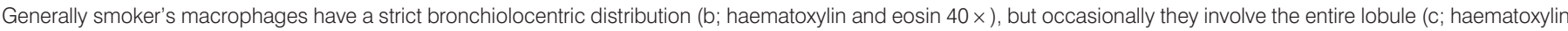

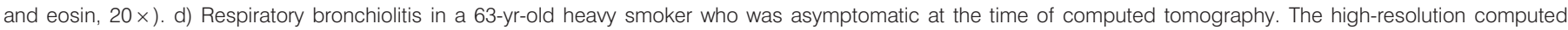


large number of eosinophils are present and the limits with chronic eosinophilic pneumonia are sometimes blurred (haematoxylin and eosin, $200 \times$ ).

Once the clinician has established the presence of an ILD due to RB, the distinction between RB-ILD and DIP is mostly based on the extension of smoker's macrophages: in RB-ILD the latter are restricted to the centrilobular area, whereas in DIP they involve the lobule more diffusely. Moreover, interstitial fibrosis (see below), lymphoid follicles, giant cells and eosinophils are more frequent in DIP than RB-ILD [13, 18]. In some patients with DIP the number of eosinophils (both in tissue and BAL) is high enough to raise concern about the possibility of chronic eosinophilic pneumonia (fig. 1e). However, the limits between RB-ILD and DIP are blurred and in practice the distinction can be difficult and, in some cases, is probably quite arbitrary; depending on sampling, the degree of alveolar filling from smoker's macrophages can vary from one lobule to another. Due to this, some authors suggest that RB-ILD and DIP should be grouped into one category [10]. However, we share the opinion of the majority that they should be classified separately whenever possible because of the differences in clinical presentation and prognosis, acknowledging that in rare cases the distinction is impossible [40]. On HRCT, RB-ILD differs from DIP in that ground-glass attenuation of RB-ILD is usually less extensive, more patchy and more poorly defined. A peripheral, sub-pleural and basal predominance of ground-glass opacity reflecting either accumulation of intra-alveolar macrophages or septal thickening is most commonly seen in DIP [7]. Although HRCT features can be useful in identifying probable DIP rather than RB-ILD, the overlapping features on HRCT scans in some cases and the occasional histological coexistence of the two entities further emphasise the need for an integrated clinical, radiological and pathological approach to secure a correct diagnosis [42].

\section{Fibrosis and emphysema}

The tendency for cigarette smokers to develop limited or extensive interstitial fibrosis is increasingly being reported by radiological and histological studies. In an accurate histological study on surgical resections performed for lung cancer, KAWABATA et al. [43] found foci of fibrosis with usual interstitial pneumonia (UIP) pattern in the non-neoplastic lung in $21.3 \%$ of smokers (125 out of 587), frequently without overt clinical features of ILD (only 49 patients had a pre-operative clinical diagnosis of IPF). No long-term follow-up was provided so the significance of this finding is unknown but, interestingly, all the patients who developed acute respiratory failure following surgery had UIP foci at histology. It is worth noting that, in a very different clinical setting (surgical biopsy performed because of ILD), the histological diagnosis of early UIP arising in the background of chronic smoking-related abnormalities is occasionally difficult.

A recent study by WASHKO et al. [44], showed that $\sim 5 \%$ of a large cohort of smokers ( $41 \%$ met the criteria for COPD) displayed minimal sub-pleural interstitial abnormalities on HRCT. However, extensive interstitial abnormalities were found in only $0.8 \%$ of the study population [44]. Another recent study showed that the prevalence of extensive interstitial abnormalities among HRCT examinations of smokers recruited by a lung cancer screening trial was $4 \%$, with a UIPlike pattern and NSIP-like pattern reported in 0.3 and $3.7 \%$ of the cases, respectively. Intriguingly, the interstitial abnormalities increased in extent among persistent current smokers, whereas they decreased in quitters [45]. In both studies, smokers with sub-pleural changes were more likely than those 
without these abnormalities to be older. An intriguing possibility is that the lung abnormalities related to cigarette smoking are analogous to those seen in elderly nonsmokers, suggesting that cigarette smoking may have a premature ageing effect on the lungs $[38,46]$. Indirect evidence for the idea of the development of fibrotic elements as part of the ageing process has come from a study by COPLEY et al. [46], in which a basal subpleural reticular pattern was identified in $60 \%$ of HRCTs of healthy individuals aged $>75$ yrs but in none of those aged $<55$ yrs [46].

Although emphysema is classically defined as permanent airspace enlargement without "obvious" (macroscopic) fibrosis $[47,48]$, in reality some microscopic fibrosis is quite frequent in centrilobular and, particularly paraseptal emphysema, and often quite prominent $[49,50]$. KATZENSTEIN et al. [51] identified fibrosis involving $>25 \%$ of slides in 20 (60\%) extensively sampled lobectomy specimens from smokers. Importantly, the authors noted that fibrosis, although sometimes histologically quite dramatic, did not produce clear clinical abnormalities, being an incidental finding in smokers undergoing operations for other reasons. Reported in the literature with terms (RB-ILD with fibrosis [24], airspace enlargement with fibrosis [43], smoking-related interstitial fibrosis [51]), fibrosis in this setting has a typical dense, amyloid-like character and is more prominent in sub-pleural and peribronchiolar parenchyma, where it frequently surrounds emphysematous spaces (fig. 2a and b). Sometimes large emphysematous holes are criss-crossed by bands of fibrosis. Fibrosis that is not associated with emphysema can also occur.

Limited fibrosis combined with pulmonary emphysema may be too fine to be seen on HRCT images. However, mild groundglass opacification and fine intralobular reticulation may be observed in confined emphysematous areas on HRCT images (fig. 2c). Future investigations are needed to assess this type of HRCT pattern. Nonetheless, it has been shown that diffuse fibrosing interstitial pneumonia, most commonly UIP, occurs in patients with emphysema. COTTIN et al. [30] have proposed that such cases fall under the subheading of CPFE, which may have distinctive clinical implications (e.g. increased incidence of pulmonary hypertension as compared to similar forms without emphysema). Differentiation of NSIP from UIP by HRCT becomes more difficult in cigarette smokers with emphysema. In a study of 54 patients with NSIP and 42 patients with UIP, the computed tomography diagnosis was correct in $44 \%$ of readings in those with concurrent emphysema, compared with $68 \%$ in those without concurrent emphysema [52].

In some smokers with ILD, fibrosis is so prominent that it makes the differential diagnosis between DIP and fibrotic NSIP difficult, both histologically and radiologically. Moreover, some authors suggest that DIP can evolve into NSIP [8], and that some cases of fibrotic NSIP can be related to tobacco smoke. In a retrospective HRCT study, MARTEN et al. [26] compared the prevalence and extent of emphysema in smokers with NSIP versus smokers with COPD and "healthy" smokers. The authors reported emphysema in a striking majority of NSIP cases $(77.8 \%)$ and COPD cases $(73.5 \%)$ but not so in the "healthy" smokers (17.5\%). The high prevalence of emphysema in the NSIP patients, which did not differ from the COPD controls, provided indirect support for a smoking pathogenetic hypothesis in some NSIP patients. Although compelling, these hypotheses are as yet unproven. In our practice we try to separate DIP and fibrotic NSIP whenever possible, particularly because the prognosis of DIP appears to be better than fibrotic NSIP, again acknowledging that, in occasional cases, the distinction is difficult and probably arbitrary.

\section{Increase in LCs}

Another common effect of smoking is the increase in the number of LCs, which are detectable in lung tissue and BAL. LCs are characteristic both on morphology (moderate amount of pale cytoplasm, deeply infolded nuclei) and immunophenotype (positivity for S-100 protein, CD1a and Langerin [53]). By definition, in PLCH LCs form clusters, but the limits between PLCH and a simple increase in LCs in a smoker are conventional and sometimes blurred. PLCH occurs when LCs accumulate in the bronchiolar wall (fig. 3a) and disperse into the surrounding alveolar septa, forming multiple stellate nodules centred on small airways (fig. 3b) [54, 55]. On HRCT, nodules are usually $<5 \mathrm{~mm}$ in diameter, and have a peribronchiolar and centrilobular distribution. The extent of nodular lesions on HRCT is strongly correlated with the density of lesions in the bioptic specimens [56].

Together with LCs, these cellular nodules frequently incorporate a variable number of eosinophils and smoker's macrophages, both in surrounding alveolar spaces and in the interstitium. An associated RB is almost universal and sometimes extensive,
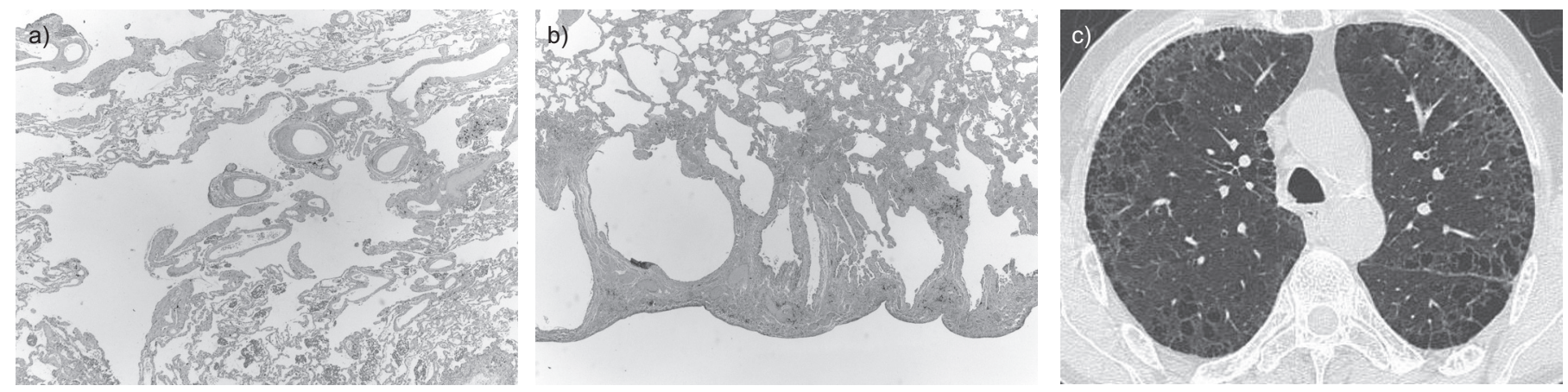

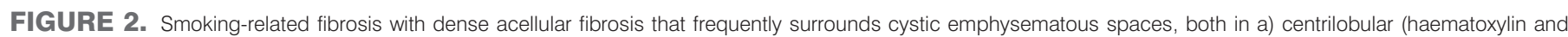


resolution computed tomography image showing mild ground-glass opacity and reticulation circumscribing emphysematous areas 
a)
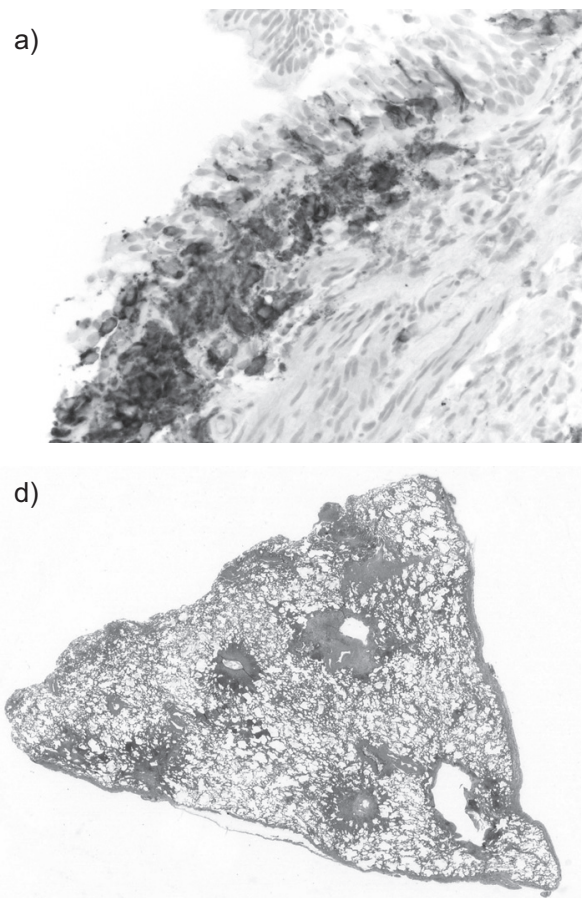




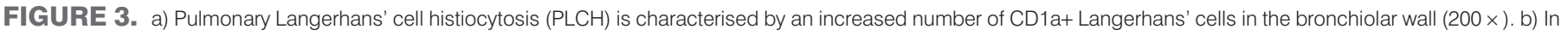

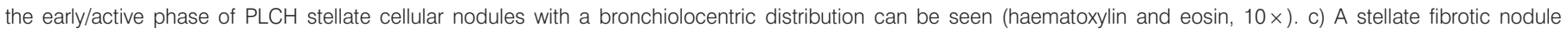

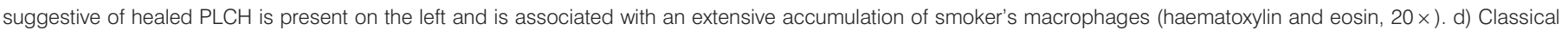

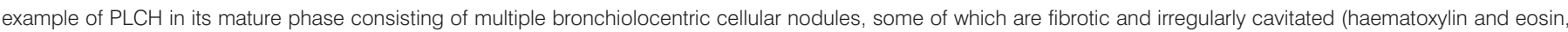


f) Chronic PLCH showing stellate scars with paracicatricial emphysema (haematoxylin and eosin, $40 \times$ ).

being visible on computed tomography scans as ground-glass opacities (fig. 3c) [42]. Over time, the centre of the nodules becomes fibrotic and irregular cavities develop in some of the nodules, leading to the classical histological features of mature $\mathrm{PLCH}$, multiple stellate nodules, some of which are cavitated and surrounded by normal lung (fig. 3d). HRCT images closely mirror the pathologic findings, showing some of the nodules that cavitate. In more advanced stages, the HRCT appearance is characterised by a cystic-nodular pattern mostly involving the upper lobes, which usually permits a confident diagnosis (fig. 3e). Nodules and cysts can occur independently of each other, but in the majority of patients they are found concomitantly. However, end-stage PLCH, when the distribution characteristics are less obvious, may be difficult to distinguish radiologically from other cystic lung diseases, such as lymphangioleiomyomatosis (in females), lymphocytic interstitial pneumonia and, above all, emphysema [57].

The outcome of these lesions varies from case to case, probably depending on the abstinence from smoking and from individual predisposition. In many cases the nodules reabsorb completely or form small bronchiolocentric scars with paracicatricial emphysema (fig. 3f). It is reasonable to assume that some cases of centrilobular emphysema with fibrosis are in reality examples of healed PLCH. Recent observations show that even cystic lesions in PLCH, as observed on HRCT, harbour active granulomas on histopathology regardless of their wall thickness, and may show improvement on serial computed tomography controls [58]. In a minority of patients progressive fibrosis develops; the stellate shape of the scars, their bronchiolocentric distribution with a prevalence in the upper lobes, and the absence/ paucity of fibroblastic foci are characteristic of chronic PLCH and are sufficient for a firm diagnosis in the majority of the cases, even in the absence of residual LCs. Occasionally, however, the histological differential diagnosis with UIP is difficult and requires a strict correlation with clinical-radiological findings. As for RB, emphysema and fibrosis, PLCH can also be a histological incidental finding in the lung specimen removed for another disease, for example carcinoma.

\section{Summary of histological and radiological findings}

As we have seen, tobacco smoke can cause many histological and radiological abnormalities (table 1). These abnormalities can be variably combined, creating a significant overlap among the different entities. Moreover, they frequently provide a backdrop for other diseases that are more clinically relevant. For these reasons, in order to establish the significance of histological and radiological findings a close correlation with clinical data is mandatory.

\section{Clinical and functional aspects in RB-ILD and DIP}

Patients with RB-ILD or DIP are usually 30-40 yrs of age and have an average smoking history of 30 pack-yrs [7, 11]; males are affected approximately twice as often as females [59, 60]. Symptoms and clinical aspects in both these diseases are nonspecific. Slowly progressive exertional dyspnoea and cough (which may be not productive) are the most frequent symptoms of presentation $[5,6,11,40]$. The presence of symptoms, mainly 


\begin{tabular}{|c|c|}
\hline Histology & HRCT \\
\hline alveolar spaces, mild bronchiolar fibrosis and inflammation & Patchy ground-glass opacity \\
\hline $\begin{array}{l}\text { Mild distortion of bronchiolar lumens with bronchioloectasia and } \\
\text { mucostasis }\end{array}$ & $\begin{array}{l}\text { Mild bronchial dilatation with wall thickening; mild air-trapping at expiratory } \\
\text { computed tomography scanning }\end{array}$ \\
\hline $\begin{array}{l}\text { Dense interstitial fibrosis, frequently surrounding } \\
\text { emphysematous holes }\end{array}$ & $\begin{array}{l}\text { Peripheral and intralobular reticulation, ground-glass opacity intermingled with } \\
\text { emphysematous areas }\end{array}$ \\
\hline $\begin{array}{l}\text { Increase in Langerhans' cells forming stellate bronchiolocentric } \\
\text { nodules, some of which are irregularly cavitated and fibrotic }\end{array}$ & III-defined or cavitated centrilobular nodules \\
\hline
\end{tabular}

in RB-ILD, is not consistent; the disease may be diagnosed in asymptomatic patients with functional impairment, end-inspiratory crackles on pulmonary examination and chest radiograph or HRCT abnormalities [40]. Bilateral basal inspiratory crackles are frequent ( $\sim 50-60 \%$ of DIP cases, rarer in RB-ILD), whereas clubbing is rare [6].

Despite the bronchiolocentric nature of disease in RB-ILD, both restrictive and obstructive alterations have been described $[5,6]$, with a mixed, predominantly restrictive, ventilator defect, usually associated with a mild-to-moderate reduction in $\mathrm{DL}, \mathrm{CO}$, the most frequent finding $[5,6]$. There is no complete correspondence between histological and functional severity of disease; some patients with near normal pulmonary functional evaluation have moderately extensive fibrotic change radiating from the bronchioles at lung biopsy [4]. However, this is likely to reflect the problem of sampling error [40, 61], with histological severity at biopsy not representative of the severity of the lung involvement. In DIP, the functional abnormality is predominantly restrictive with the $D L, C O$ reduction a useful guide to the underlying severity of the disease. An important confounder in the interpretation of functional impairment in both RB-ILD and DIP is the frequent concomitant presence of emphysema. In these cases, the presence of emphysema may justify a predominantly obstructive defect on pulmonary function tests. A mild obstructive alteration may be due to concomitant chronic bronchiolitis. In other cases the co-existence of emphysema and fibrotic changes may give rise to paradoxically normal lung volumes associated with a disproportionate reduction in DL,CO [5, 6].

\section{Clinical and functional aspects in PLCH}

PLCH is a rare disease [62]. The classification of histiocytic disorders has been simplified and is based on the presence of single or multi-organ involvement [63]. In the latter case, lung disease is most commonly found in children and is not associated with smoking. The significant clinical and epidemiological differences between the pulmonary and systemic forms of the disease suggest that although the pivotal cell may be the same (LC), the pathogenetic pathways are different [63-67]. More than 90\% of patients with isolated PLCH are current or former smokers [63-67]. Although the proposed pathogenesis of PLCH revolves around an immune response involving locally recruited LCs and other inflammatory/immune cells, the trigger for cellular proliferation appears to be an inhaled antigen, probably residing in tobacco smoke $[67,68]$. This hypothesis is supported by the peribronchiolar distribution of the lesions in this disease. LCs are differentiated antigenpresenting cells of monocyte-machrophage lineage occurring in the normal lung [63]. The origin of the expanded population of LCs in the lungs is unknown. The increase of LCs may be due to local proliferation of the cells but a more important mechanism is considered to be accumulation, through enhanced recruitment of circulating precursors and delayed apoptosis [69-72]. Recently, a report demonstrated that $50 \%$ of patients with LC histiocytosis have a somatic mutation of the oncogene BRAF, V600E. This observation strongly suggests that LC histiocytosis is a neoplastic disease [73]. The presence of BRAF V600E in PLCH was surprising considering the fact that $70 \%$ of pulmonary diseases have been reported to be polyclonal; the significance of this observation is not well understood. PLCH probably represents a polyclonal reaction to cigarette smoking in predisposed individuals [74]. Not surprising, many patients with PLCH frequently show RB/DIP-like reactions in lung biopsies. The disease affects young adults between 20 and 40 yrs of age. No clear sex predominance of the disease has been described. Patient's presentation consists of dyspnoea, dry cough and chest pain, as well as constitutional symptoms (fever, malaise and weight loss) but the disease may be asymptomatic (in $\sim 25 \%$ of patients) $[63,65]$. In the latter case, abnormal chest radiographs are the only alterations and chest radiography is performed for other reasons. Haemoptysis is an unusual symptom in PLCH and should lead to investigations for an alternative diagnosis or superimposed lung carcinoma in these smoking patients. Measures of $\mathrm{DL}, \mathrm{CO}$ are more sensitive in detecting lung involvement than lung volumes measurements, which could show normal, obstructive, restrictive or mixed patterns $[60,75,76]$. A recent study shows that airway obstruction was the prevalent pattern of lung function defect observed at diagnosis and during follow-up [77]. Cystic bone lesions may be identified in $\sim 10 \%$ of patients and may precede the development of lung disease [60]. Diabetes insipidus and skin lesions may be present [63]. Pneumothorax with chest pain is the initial clinical presentation in $15 \%$ of patients with PLCH and may be recurrent, requiring chest tube placement and thoracotomy [78]. Pleurodesis is often required because of the high rate of recurrence. Physical examination is usually indifferent except in cases of pneumothorax. Pulmonary hypertension is more prominent in advanced PLCH than in other 
chronic lung diseases owing to direct intrinsic pulmonary vascular/vasculitic involvement [79, 80]. PLCH has been described in association with lung cancer as well as extrapulmonary cancers and lymphoma, especially Hodgkin disease $[67,81,82]$. Neoplasms may be either synchronous with PLCH, precede it or appear at another time. The occurrence of lung cancer and other tobacco smoke-associated malignancies probably reflects the impact of smoking as a common aetiological agent for each disease [67]. Prior treatment with chemotherapeutic agents and chromosomal or genetic abnormalities are factors that may confer a predisposition to the development of malignant neoplasms in patients with PLCH. Clinical and functional aspects of RB-ILD, DIP and PLCH in comparison with CPFE are shown in table 2.

\section{The role of BAL}

BAL examination represents an important step in the diagnosis of ILD [83]. In the majority of cases, the results of BAL fluid examination only provide additional information and cannot be used as the basis for definitive diagnosis of ILD. However, this relatively noninvasive procedure is very useful in the differential diagnosis of ILD; the normal cellular count of BAL excludes active inflammation. The typical pathological features in smoking-related ILD, RB-ILD and DIP is an important and significant increase in total cells counts and in the number of pigmented alveolar macrophages. The frequent observation in
DIP is an increase in the percentage of eosinophils and neutrophils. The BAL findings are not specific or diagnostic.

In PLCH the finding of $>5 \%$ of LCs in BAL strongly suggests the diagnosis in the appropriate clinical-radiological setting. This cut-off distinguishes between patients with PLCH and smokers without PLCH and other ILDs but reduces the test sensibility [84, 85]. In our series of 27 patients with a diagnosis of PLCH, bronchoscopic evaluation with BAL was performed in 16 patients and BAL was diagnostic in four (25\%) cases (unpublished data). Our results are in agreement with data in which a BAL sensitivity of $<25 \%$ is reported in PLCH diagnosis. In PLCH, a macrophagic alveolitis that reflects the smoking history of the patients is typically present.

\section{DIAGNOSTIC WORK-UP OF PATIENTS WITH SUSPECTED SMOKING-RELATED ILDS \\ Diagnosis of RB-ILD and DIP}

The diagnosis of RB-ILD is essentially a clinical-functionalradiological-histological diagnosis and is based on global markers of disease severity (symptoms, pulmonary functional impairment and HRCT abnormalities), not on histological evaluation in isolation. RB-ILD is histologically indistinguishable from RB and $\mathrm{RB}$ is a very common, and possibly incidental, finding in cigarette smokers. The discovery of RB on lung biopsy is not equivalent to a diagnosis of RB-ILD. Since the clinical features of RB-ILD may be confused with other ILDs and the imaging

\section{TABLE 2}

Clinical features of respiratory bronchiolitis-interstitial lung disease (RB-ILD), desquamative interstitial pneumonia (DIP) and pulmonary Langerhans' cell histiocytosis (PLCH) in comparison with combined pulmonary fibrosis and emphysema (CPFE)

\begin{tabular}{|c|c|c|c|c|}
\hline & RB-ILD & DIP & PLCH & CPFE \\
\hline Smoking & $100 \%$ & $90 \%$ & $>90 \%$ & $100 \%$ (heavy smokers) \\
\hline Age & 3rd to 5 th decade & 3rd to 5 th decade & 3rd to 4 th decade & 6 th to 7 th decade \\
\hline Sex M:F & Slight male dominance & Nearly $2: 1$ & $1: 1$ & Almost all male \\
\hline Onset & Insidious & Insidious & Insidious & Insidious \\
\hline Presenting symptoms & Dyspnoea and cough & Dyspnoea and cough & $\begin{array}{c}\text { Dyspnoea, cough and acute chest } \\
\text { pain (when pneumothorax is } \\
\text { present) }\end{array}$ & Dyspnoea and cough \\
\hline Systemic involvement & No & Possible, rare & Possible & No \\
\hline Crackles & $\sim 50 \%$ & $60 \%$ & Usually absent & $87 \%$ basal \\
\hline Clubbing & Rare & Nearly $50 \%$ & Exceptional & $43 \%$ \\
\hline Pulmonary function & $\begin{array}{l}\text { Mixed defect or normal; } \\
\text { reduced DL,CO }\end{array}$ & Restrictive; reduced DL,co & $\begin{array}{l}\text { Obstructive or restrictive; reduced } \\
\text { DL,Co (especially in patients with } \\
\text { vascular involvement) }\end{array}$ & $\begin{array}{l}\text { Sub-normal pulmonary volumes; } \\
\text { severe reduction of } D \mathrm{~L}, \mathrm{CO}\end{array}$ \\
\hline Pulmonary hypertension & No & Rare & Possible & $\begin{array}{c}47 \% \text { at diagnosis; between } 50 \% \\
\text { and } 90 \%\end{array}$ \\
\hline Desaturation on 6MWT & No & Possible & Rare & Frequent \\
\hline Spontaneous improvement & Possible & Occasionally & Possible & No \\
\hline Treatment & Smoking cessation & Smoking cessation and steroids & Smoking cessation and steroids? & Smoking cessation \\
\hline Response to steroids & Good & Good & Fair & None \\
\hline Prognosis & Good & Good & Good & Poor (5-yr survival is $55 \%$ ) \\
\hline Complete recovery possible & Yes & Yes & Yes & No \\
\hline $\begin{array}{l}\text { Correlation with lung cancer } \\
\text { or other neoplasms }\end{array}$ & No & Rare & Frequent & Frequent (near 50\%) \\
\hline
\end{tabular}

M: male; F: female; 6MWT: 6-min walk test; DL,CO: diffusing capacity of the lung for carbon monoxide. 
features overlap with other entities, such as hypersensitivity pneumonitis, the diagnosis sometimes requires lung biopsy. In the differential diagnosis between RB-ILD and hypersensitivity pneumonitis, the history (RB-ILD occurs nearly only in smokers whereas hypersensitivity pneumonitis is rare in smokers) and BAL profile (macrophagic alveolitis is observed in RB-ILD and lymphocytosis in hypersensitivity pneumonitis) are usually definitive in distinguishing between these disorders. History, HRCT and BAL findings usually allow diagnosis of RB-ILD without the need for a lung biopsy. In the appropriate clinicalradiological contest, a transbronchial biopsy that shows only the characteristic aspects of RB may suggest the diagnosis of RBILD. By contrast, lung biopsy is generally required to diagnose DIP as the HRCT aspects of extensive ground-glass attenuation and the highly cellular BAL profile are both nonspecific [18]. It is important to remember that both DIP and RB-ILD are closely related to cigarette smoking and their histological features may be seen in association with other interstitial disease $[4,18,41$, 43]. DIP and RB-ILD should be diagnosed only in the absence of aspects suggestive of other ILDs [4, 18, 41, 43]. Patients with DIP may develop, in the long term, a HRCT pattern of fibrotic NSIP, suggesting that NSIP could be considered a new smokingrelated interstitial lung disease [8]. However, the proposed relationship of DIP to fibrotic NSIP remains uncertain. The prognosis of DIP appears to be significantly better than that of fibrotic NSIP, so while there can be morphological overlap between the two, merging them into one disease may hide important prognostic information [8].

\section{Diagnosis of PLCH}

The HRCT appearance in PLCH is diagnostic in most cases. The simultaneous presence of multiple nodules, cavitated nodules and cystic spaces with an upper lung predominance and sparing of the lung bases in a young heavy smoker man is characteristic of PLCH. In end-stage disease, when only diffuse cysts with no nodules are present, the radiological diagnosis is more difficult. BAL analysis may be useful if $>5 \%$ of CD1a cells are found, but this is more frequent in early stages of the disease. In the presence of a radiological cystic lung disease, macrophagic alveolitis on BAL examination may support the diagnosis of PLCH. In case of another type of alveolitis in BAL, the diagnosis should be reconsidered. In a small number of cases, the diagnosis of PLCH may be obtained on transbronchial biopsy, in the presence of the appropriate clinical and radiological setting $[85,86]$. In our series of 27 patients with PLCH, transbronchial biopsy was performed in three cases and a diagnosis of PLCH was established in only one (33\%) case (unpublished data). Our limited data are consistent with the literature where transbronchial biopsy is diagnostic in 10-40\% of cases. Confirmation of PLCH on transbronchial biopsy requires a high index of suspicion and reliance on immunohistochemical demonstration of aggregates of LCs in the tissue [86] or the recognition of stellate scars around the bronchioles. The low diagnostic yield of transbronchial biopsy is partly due to patchy distribution of the PLCH lesions and, in advanced stages of disease, to the non-specificity of the histological features, particularly in a small biopsy sample $[67,86]$. In clinical and/or radiological atypical cases, lung biopsy is necessary for a definitive diagnosis. A confounding issue in the diagnosis of PLCH by surgical lung biopsy is the exclusive presence of end-stage fibrotic changes in which LCs are scare or absent [87]. When this occurs, the diagnosis of PLCH may be suggested based on the histological pattern of discrete bronchiolocentric stellate scars with appropriate radiological correlation. In lung biopsies of patients with PLCH one may observe RB-/DIP-like changes as a consequence of pulmonary injury associated with cigarette smoke and occasionally these aspects may be sufficiently severe to cause ground-glass attenuation on HRCT scanning and complicate the radiological diagnosis [42].

\section{TREATMENT AND PROGNOSIS RB-ILD and DIP}

Patients with RB-ILD usually do not need any specific treatment other than smoking cessation. Progressive evolution to fibrotic lung disease does not seem to occur and no deaths have been attributed, with certainty, to RB-ILD $[5,11]$. In case of progression of disease, steroids may be useful [88]. Spontaneous improvement has been observed in some patients with DIP, possibly related to smoke cessation. There is clinical deterioration in approximately two-thirds of patients with DIP who are untreated [11,89]. The mainstay of treatment in patients with DIP consists of corticosteroid therapy, which may cause stabilisation or improvement of the disease. Complete recovery of the disease has been described $[59,89]$. In $\sim 25 \%$ of patients, however, progression of disease may be observed despite steroid therapy [11, 59, 89] and lung transplantation may be an option. Recurrence has also been reported in patients who have received a lung transplant [90].

\section{$\mathrm{PLCH}$}

Smoking cessation leads to radiological improvement and even complete recovery in early cellular and nodular cases of PLCH $[89,91,92]$. The disease may improve with smoking cessation alone; the 5- and 10-yr survival rate is $74.6 \%$ and $63.9 \%$, respectively [93]. There have been no randomised trials comparing the efficacy of corticosteroids with that of smoking cessation alone in PLCH, and it is therefore difficult to establish the benefit of these two options. However, a subset of patients experience progressive disease; in these cases therapy still remains unsatisfactory and may include steroids and/or cytotoxic agents (methotrexate, cyclophosphamide, vinblastine, chlorambucil, etoposide and, 2-chlorodeoxyadenosine) $[63,66,68]$. Randomised trials valuating the efficacy of each of these therapies are lacking. These drugs should be reserved as salvage therapy for patients with progressive and severe disease. Recently, 2-chlorodeoxyadenosine (cladribine) was suggested as a promising treatment [94] and a randomised trial is currently ongoing in symptomatic patients with lung function impairment (www.clinicaltrials.gov NCT01473797). Patients with progressive disease associated with severe respiratory impairment and who are unresponsive to steroid therapy or chemotherapeutic agents should be considered for lung transplantation [95]. Patients should stop smoking before lung transplantation, as there is evidence of PLCH recurrence in the transplanted lung if smoking is resumed [92]. The disease may also recur in nonsmokers, especially in patients with extrapulmonary involvement [95]. The course of PLCH is variable and difficult to predict in the single patient. Prognostic factors of the disease are not well-known but obstruction, air-trapping and reduced $D \mathrm{~L}, \mathrm{CO}$ on pulmonary function tests at diagnosis appear to be helpful in identifying patients with a poor prognosis $[96,97]$. 
Other poor prognostic factors are older age at diagnosis and corticosteroid therapy during follow-up $[96,97]$. Severe pulmonary hypertension is a frequent complication in patients with advanced PLCH. Recent observations suggest that therapy with bosentan [98] and other therapies utilised for idiopathic pulmonary hypertension may be indicated in these patients [99]. Fludeoxyglucose-positron emission tomography/computed tomography images have been proposed as a new noninvasive methodology for monitoring disease activity and response to therapy [100, 101].

\section{STATEMENT OF INTEREST}

S. Harari has relationships with drug companies including Actelion, InterMune and GSK. In addition to being an investigator in trials involving these companies, relationships include consultancy service and membership of scientific advisory boards.

\section{REFERENCES}

1 Visscher DW, Myers JL. Bronchiolitis: the pathologist's perspective. Proc Am Thorac Soc 2006; 3: 41-47.

2 Wright JL, Cagle P, Churg A, et al. Diseases of the small airways. Am Rev Respir Dis 1992; 146: 240-262.

3 Shaw RJ, Djukanovic R, Tashkin DP, et al. The role of small airways in lung disease. Respir Med 2002; 96: 67-80.

4 Fraig M, Shreesha U, Savici D, et al. Respiratory bronchiolitis: a clinicopathologic study in current smokers, ex-smokers, and never-smokers. Am J Surg Pathol 2002; 26: 647-653.

5 Myers JL, Veal CF Jr, Shin MS, et al. Respiratory bronchiolitis causing interstitial lung disease: a clinical pathologic study of six cases. Am Rev Respir Dis 1987; 135: 880-884.

6 Moon J, du Bois RM, Colby TV, et al. Clinical significance of respiratory bronchiolitis on open lung biopsy and its relationship to smoking related interstitial lung disease. Thorax 1999; 54: 1009-1014.

7 Heyneman LE, Ward S, Lynch DA, et al. Respiratory bronchiolitis, respiratory bronchiolitis-associated interstitial lung disease, and desquamative interstitial pneumonia: different entities or part of the spectrum of the same disease process? AJR Am J Roentgenol 1999; 173: 1617-1622.

8 Craig PJ, Wells AU, Doffman S, et al. Desquamative interstitial pneumonia, respiratory bronchiolitis and their relationship to smoking. Histopathology 2004; 45: 275-282.

9 Mang CM, Grosse C, Schmid K, et al. What every radiologist should know about idiopathic interstitial pneumonias. Radiographics 2007; 27: 595-615.

10 Myers JL, Katzenstein AL. Beyond a consensus classification for idiopathic interstitial pneumonias: progress and controversies. Histopathology 2009; 54: 90-103.

11 Yousem S, Colby T, Gaensler E. Respiratory bronchiolitis-associated interstitial lung disease and its relationship to desquamative interstitial pneumonia. Mayo Clin Proc 1989; 64: 1373-1380.

12 Elkin SL, Nicholson AG, du Bois RM. Desquamative interstitial pneumonia and respiratory bronchiolitis-associated interstitial lung disease. Semin Respir Crit Care Med 2001; 22: 387-398.

13 Kawabata Y, Takemura T, Hebisawa A, et al. Eosinophilia in bronchoalveolar lavage fluid and architectural destruction are features of desquamative interstitial pneumonia. Histopathology 2008; 52: 194-202.

14 Portnoy J, Veraldi KL, Schwarz MI, et al. Respiratory bronchiolitisinterstitial lung disease: long-term outcome. Chest 2007; 131: 664-671.

15 Ryu JH, Myers JL, Capizzi SA, et al. Desquamative interstitial pneumonia and respiratory bronchiolitis-associated interstitial lung disease. Chest 2005; 127: 178-184.
16 Yogo Y, Oyamada Y, Ishii M, et al. A case of acute exacerbation of desquamative interstitial pneumonia after video-assisted thoracoscopic surgery (VATS). J Japan Resp Soc 2003; 41: 386-391.

17 Sánchez Varilla JM, Vázquez Martin M, Garcia Dante H, et al. Exacerbacion aguda de un caso de neumonitis intersticial descamativa tras biopsia pulmonar por videotorascoscopia [Acute exacerbation of desquamative interstitial pneumonia after thoracoscopy lung biopsy]. Ann Med Intern 2005; 22: 604-605.

18 Tazelaar HD, Wright JL, Churg A. Desquamative interstitial pneumonia. Histopathology 2011; 58: 509-516.

19 Demedts M, Costabel U. ATS/ERS international multidisciplinary consensus classification of the idiopathic interstitial pneumonias. Eur Respir J 2002; 19: 794-796.

20 Ishii $\mathrm{H}$, Iwata $\mathrm{A}$, Sakamoto $\mathrm{N}$, et al. Desquamative interstitial pneumonia (DIP) in a patient with rheumatoid arthritis: is DIP associated with autoimmune disorders? Intern Med 2009; 48: 827-830.

21 Beasley MB. Smoking-related small airway disease-a review and update. Adv Anat Pathol 2010; 17: 270-276.

22 Pappas K. Bronchiolitis and bronchial disorders in interstitial lung disease. Curr Opin Pulm Med 2011; 17: 316-324.

23 Kambouchner M, Basset F, Marchal J, et al. Three-dimensional characterization of pathologic lesions in pulmonary Langerhans cell histiocytosis. Am J Respir Crit Care Med 2002; 166: 1483-1490.

24 Yousem SA. Respiratory bronchiolitis-associated interstitial lung disease with fibrosis is a lesion distinct from fibrotic nonspecific interstitial pneumonia: a proposal. Mod Pathol 2006; 19: 1474-1479.

25 Hansell DM, Nicholson AG. Smoking-related diffuse parenchymal lung disease: HRCT-pathologic correlation. Semin Respir Crit Care Med 2003; 24: 377-392.

26 Marten K, Milne D, Antoniou KM, et al. Non-specific interstitial pneumonia in cigarette smokers; a CT study. Eur Radiol 2009; 19: 1679-1685.

27 Galvin JR, Franks TJ. Smoking-related lung disease. J Thorac Imaging 2009; 24: 274-284.

28 Shorr AF, Scoville SL, Cersovsky SB, et al. Acute eosinophilic pneumonia among US military personnel deployed in or near Iraq. JAMA 2004; 292: 2997-3005.

29 Cottin V, Nunes H, Brillet PY, et al. Combined pulmonary fibrosis and emphysema: a distinct under recognized entity. Eur Respir J 2005; 26: 586-593.

30 Cottin V, Le Pavec J, Prévot G, et al. Pulmonary hypertension in patients with combined pulmonary fibrosis and emphysema syndrome. Eur Respir J 2010; 35: 105-111.

31 Balbi B, Cottin V, Singh S, et al. Smoking-related lung diseases: a clinical perspective. Eur Respir J 2010; 35: 231-233.

32 Harari S, Caminati A. Update on diffuse parenchymal lung disease. Eur Respir Rev 2010; 19: 97-108.

33 Myers JL. Respiratory bronchiolitis with interstitial lung disease. Semin Respir Med 1992; 13: 134-139.

34 Caminati A, Graziano P, Sverzellati N, et al. Smoking-related interstitial lung diseases. Pathologica 2010; 102: 525-536.

35 Gill A. Bong lung: regular smokers of cannabis show relatively distinctive histologic changes that predispose to pneumothorax. Am J Surg Pathol 2005; 29: 980-982.

36 Remy-Jardin M, Remy J, Gosselin B, et al. Lung parenchymal changes secondary to cigarette smoking: pathologic-CT correlations. Radiology 1993; 186: 643-651.

37 Remy-Jardin M, Remy J, Boulenguez C, et al. Morphologic effects of cigarette smoking on airways and pulmonary parenchyma in healthy adult volunteers: CT evaluation and correlation with pulmonary function tests. Radiology 1993; 186: 107-115.

38 Hansell DM. Small airways diseases: detection and insights with computed tomography. Eur Respir J 2001; 17: 1294-1313.

39 Hansell DM. Thin-section CT of the lungs: the Hinterland of normal. Radiology 2010; 256: 695-711. 
40 Wells AU, Nicholson AG, Hansell DM. Challenges in pulmonary fibrosis. 4: smoking-induced diffuse interstitial lung diseases. Thorax 2007; 62: 904-910.

41 Churg A, Muller NL, Wright JL. Respiratory bronchiolitis/ interstitial lung disease. Fibrosis, pulmonary functions, and evolving concepts. Arch Pathol Lab Med 2010; 134: 27-32.

42 Vassallo R, Jensen EA, Colby TV, et al. The overlap between respiratory bronchiolitis and desquamative interstitial pneumonia in pulmonary Langerhans cell histiocytosis. High-resolution CT, histologic, and functional correlations. Chest 2003; 124: 1199-1205.

43 Kawabata $\mathrm{Y}$, Hoshi E, Murai K, et al. Smoking-related changes in the background lung of specimens resected for lung cancer: a semiquantitative study with correlation to postoperative course. Histopathology 2008; 53: 707-714.

44 Washko GR, Hunninghake GM, Fernandez IE, et al. Lung volumes and emphysema in smokers with interstitial lung abnormalities. N Engl J Med 2011; 364: 897-906.

45 Sverzellati N, Guerci L, Randi G, et al. Interstitial lung diseases in a lung cancer screening trial. Eur Respir J 2011; 38: 392-400.

46 Copley SJ, Wells AU, Hawtin KE, et al. Lung morphology in the elderly: comparative CT study of subjects over 75 years old versus those under 55 years old. Radiology 2009; 251: 566-573.

47 Snider G, Kleinerman J, Thurlbeck W, et al. The definition of emphysema. Report of a National Heart, Lung and Blood Institute division of lung diseases workshop. Am Rev Respir Dis 1985; 132: 182-185.

48 Bellomi M, Rampinelli C, Veronesi G, et al. Evolution of emphysema in relation to smoking. Eur Radiol 2010; 20: 286-292.

49 Wright JL, Tazelaar HD, Churg A. Fibrosis with emphysema. Histopathology 2011; 58: 517-524.

50 Katzenstein AL. Smoking-related interstitial fibrosis (SRIF), pathogenesis and treatment of usual interstitial pneumonia (UIP), and transbronchial biopsy in UIP. Mod Pathol 2012; 25: Suppl. 1, S68-S78.

51 Katzenstein ALA, Mukhopadhyay S, Zanardi C, et al. Clinically occult interstitial fibrosis in smokers: classification and significance of a surprisingly common finding in lobectomy specimens. Hum Pathol 2010; 41: 316-325.

52 Akira M, Inoue $\mathrm{Y}$, Kitaichi M, et al. Usual interstitial pneumonia and nonspecific interstitial pneumonia with and without concurrent emphysema: thin-section CT findings. Radiology 2009; 251: 271-279.

53 Sholl LM, Hornick JL, Pinkus JL, et al. Immunohistochemical analysis of Langerin in Langerhans cell histiocytosis and pulmonary inflammatory and infectious diseases. Am J Surg Pathol 2007; 31: 947-952.

54 Colby TV, Lombard C. Histiocytosis X in the lung. Hum Pathol 1983; 14: 847-856.

55 Cavazza A, Rossi G, Barbareschi M, et al. I macrofagi nelle malattie interstiziali del polmone: loro utilità diagnostica [Diagnostic utility of macrophages in interstitial lung disease]. Pathologica 2006; 98: 211-223.

56 Soler P, Bergeron A, Kambouchner M, et al. Is high-resolution computed tomography a reliable tool to predict the histopathological activity of pulmonary Langerhans cell histiocytosis? Am J Respir Crit Care Med 2000; 162: 264-270.

57 Koyama M, Johkoh T, Honda O, et al. Chronic cystic lung disease: diagnostic accuracy of high-resolution $\mathrm{CT}$ in 92 patients. AJR Am J Roentgenol 2003; 180: 827-835.

58 Kim HJ, Lee KS, Johkoh T, et al. Pulmonary Langerhans cell histiocytosis in adults: high-resolution CT-pathology comparisons and evolutional changes at CT. Eur Radiol 2011; 21: 1406-1415.

59 Hartmann TE, Primack SL, Kang EY, et al. Disease progression in usual interstitial pneumonia compared with desquamative interstitial pneumonia. Chest 1996; 110: 378-382.
60 Hidalgo A, Franquet T, Gimenez A, et al. Smoking-related interstitial lung diseases: radiologic-pathologic correlation. Eur Radiol 2006; 16: 2463-2470.

61 Flaherty KR, Travis WD, Colby TV, et al. Histologic variability in usual and nonspecific interstitial pneumonias. Am J Respir Crit Care Med 2001; 164: 1722-1727.

62 Gaensler EA, Carrington CB. Open biopsy for chronic diffuse infiltrative lung disease: clinical, roentgenographic, and physiological correlations in 502 patients. Ann Thorac Surg 1980; 30: 411-426.

63 Vassallo R, Ryu JH, Colby TV, et al. Pulmonary Langerhans cell histiocytosis. N Eng J Med 2000; 342: 1969-1978.

64 Soler P, Kambouchner M, Valeyre D, et al. Pulmonary Langerhans' cell granulomatosis (histiocytosis X). Annu Rev Med 1992; 43: 105-115.

65 Travis WD, Borok Z, Roum JH, et al. Pulmonary Langerhans cell granulomatosis (histiocytosis $\mathrm{X}$ ): a clinicopathologic study of 48 cases. Am J Surg Pathol 1993; 17: 971-986.

66 Tazi A, Soler P, Hance AJ. Adult pulmonary Langerhans' cell histiocytosis. Thorax 2000; 55: 405-416.

67 Rao RN, Goodman LR, Tomashefski JF. Smoking-related interstitial lung disease. Ann Diagn Pathol 2008; 12: 445-457.

68 Soler P, Tazi A, Hance AJ. Pulmonary Langerhans cell granulomatosis. Curr Opin Pulm Med 1995; 1: 406-416.

69 Brabencova E, Tazi A, Lorenzato $\mathrm{M}$, et al. Langerhans cells in Langerhans cell granulomatosis are not actively proliferating cells. Am J Pathol 1998; 152: 1143-1149.

70 Marchal J, Kambouchner M, Tazi A, et al. Expression of apoptosisregulatory proteins in lesions of pulmonary Langerhans cell histiocytosis. Histopathology 2004; 45: 20-28.

71 Senechal B, Elain G, Jeziorski E, et al. Expansion of regulatory T cells in patients with Langerhans cell histiocytosis. PLoS Medicine 2007; 4: 1374-1384.

72 Suri HS, Yi ES, Nowakowski GS, et al. Pulmonary Langerhans cell histiocytosis. Orphanet J Rare Dis 2012; 7: 16.

73 Badalian-Very G, Vergilio JA, Degar BA, et al. Recurrent BRAF mutations in Langerhans cell histiocytosis. Blood 2010; 116: 1919-1923.

74 Yousem SA, Colby TV, Chen YY, et al. Pulmonary Langerhans' cell histiocytosis: molecular analysis of clonality. Am J Surg Pathol 2001; 25: 630-636.

75 Schönfeld N, Frank W, Wenig S, et al. Clinical and radiologic features, lung function and therapeutic results in histiocytosis $\mathrm{X}$. Respiration 1993; 60: 38-44.

76 Paciocco G, Uslenghi E, Bianchi A, et al. Diffuse cystic lung diseases: correlation between radiologic and functional status. Chest 2004; 125: 135-142.

77 Tazi A, Marc K, Dominique S, et al. Serial CT and lung function testing in pulmonary Langerhans cell histiocytosis. Eur Respir J 2012; [Epub ahead of print DOI: 10.1183/09031936.00210711].

78 Lacronique J, Roth C, Battesti JP, et al. Chest radiological features of pulmonary histiocytosis $\mathrm{X}$ : a report based on 50 adult cases. Thorax 1982; 32: 104-107.

79 Fartoukh M, Humbert M, Capron F, et al. Severe pulmonary hypertension in histiocytosis X. Am J Respir Crit Care Med 2000; 161: 216-223.

80 Harari S, Brenot F, Barberis M, et al. Advanced pulmonary histiocytosis $\mathrm{X}$ is associated with severe pulmonary hypertension. Chest 1997; 111: 1142-1144.

81 Lombard CM, Medeiros J, Colby TV. Pulmonary histiocytosis X and carcinoma. Arch Pathol Lab Med 1987; 111: 339-341.

82 Tomashefski JF, Khiyami A, Kleinerman J. Neoplasms associated with pulmonary eosinophilic granuloma. Arch Pathol Lab Med 1991; 115: 499-506.

83 American Thoracic Society, European Respiratory Society. American Thoracic Society/European Respiratory Society International Multidisciplinary Consensus Classification of the Idiopathic 
Interstitial Pneumonias. Am J Respir Crit Care Med 2002; 165 277-304.

84 Caminati A, Harari S. Smoking-related interstitial pneumonias and pulmonary Langerhans cell histiocytosis. Proc Am Thorac Soc 2006; 3: 299-306.

85 Torre $\mathrm{O}, \mathrm{Harari}$ S. The diagnosis of cystic lung diseases: a role for bronchoalveolar lavage and transbronchial biopsy? Respir Med 2010; 104: Suppl. 1, S81-S85.

86 Housini I, Tomashefski JF Jr, Cohen A, et al. Transbronchial biopsy in patients with pulmonary eosinophilic granuloma. Comparison with findings on open lung biopsy. Arch Pathol Lab Med 1994; 118: 523-530.

87 Rao RN, Chang CC, Tomashefski JF Jr. Lymphocyte subpopulations and non-Langerhans' cell monocytoid cells in pulmonary Langerhans cell histiocytosis. Pathol Res Pract 2008; 208: 315-322.

88 Ryu JH, Colby TV, Hartman TE, et al. Smoking-related interstitial lung diseases: a concise review. Eur Respir J 2001; 17: 122-132.

89 Marten K, Hansell DM. Imaging of macrophage-related lung diseases. Eur Radiol 2005; 15: 727-741.

90 Verleden GM, Sels F, Van Raemdonck D, et al. Possible recurrence of desquamative interstitial pneumonitis in a single lung transplant recipient. Eur Respir J 1998; 11: 971-974.

91 Von Essen S, West W, Sitorius M, et al. Complete resolution of roentgenographic changes in a patient with pulmonary histiocytosis X. Chest 1990; 98: 765-767.

92 Mogulkuc N, Veral A, Bishop PW, et al. Pulmonary Langerhans' cell histiocytosis: radiologic resolution following smoking cessation. Chest 1999; 115: 1452-1455.
93 Chaowalit N, Pellikka P, Decker P, et al. Echocardiographic and clinical characteristics of pulmonary hypertension complicating pulmonary Langerhans cell histiocytosis. Mayo Clin Proc 2004; 79: 1269-1275.

94 Lazor R, Etienne-Mastroianni B, Khouatra C, et al. Progressive diffuse pulmonary Langerhans cell histiocytosis improbe by cladribine chemotherapy. Thorax 2009; 64: 274-275.

95 Dauriat G, Mal H, Thabut G, et al. Lung transplantation for pulmonary Langerhans' cell histicytosis: a multicenter analysis. Transplantation 2006; 81: 746-750.

96 Vassallo R, Ryu JH, Schroeder DR, et al. Clinical outcomes of pulmonary Langerhans cell histiocytosis in adults. $N$ Engl J Med 2002; 346: 484-490

97 Harari S, Caminati A. Pulmonary Langerhans cell histiocytosis. Eur Respir Monogr 2009; 46: 155-175.

98 Kiakouama L, Cottin V, Etienne-Mastroianni B, et al. Severe pulmonary hypertension in histiocytosis $\mathrm{X}$ : long-term improvement with bosentan. Eur Respir J 2010; 36: 202-211.

99 Le Pavec J, Lorillon G, Jais X, et al. Pulmonary Langerhans cell histiocytosis associated pulmonary hypertension: clinical characteristics and impact of pulmonary arterial hypertension therapies. Chest 2012 [Epub ahead of print DOI: 10.1378/chest.11-2490].

100 Krajicek BJ, Ryu JH, Hartman TE, et al. Abnormal fluorodeoxyglucose PET in pulmonary Langerhans cell histiocytosis. Chest 2009; 135: 1542-1549.

101 Szturz P, Rehak Z, Koukalova R, et al. Measuring diffuse metabolic activity on FDG-PET/TC: new method for evaluating Langerhans cell histiocytosis activity in pulmonary parenchyma. Nucl Med Biol 2012; 39: 429-436. 